\title{
A Rare Case of Epidermoid Cyst at Suprasternal Notch in an Adult
}

\author{
Ginni Datta ${ }^{1}$, Soniya Arora², Sagar Chandra³ ${ }^{3}$ Cynthia Kaur ${ }^{4}$ \\ ${ }^{1}$ Department of ENT, MMIMSR, Mullana, Ambala, Haryana, India. ${ }^{2}$ Department of ENT, \\ MMIMSR, Mullana, Ambala, Haryana, India. ${ }^{3}$ Department of ENT, MMIMSR, Mullana, Ambala, \\ Haryana, India. ${ }^{4}$ Department of ENT, MMIMSR, Mullana, Ambala, Haryana, India.
}

\section{INTRODUCTION}

Dermoid cysts are benign entities, characterized histologically as- if it is lined by squamous epithelium, it is known as epidermoid cyst, if it contains skin adnexa, it is called true dermoid and if it contains tissue of all three germ layers like muscle, teeth, bone, cartilage it is called teratoid cyst. Prevalence is 7\% and $1.6 \%$ in head \& neck and oral cavity respectively. According to literature the term dermoid cyst can be used interchangeably for any of the three histologically distinct entities. They occur at areas of embryonic fusion. Dermoid cyst are classified into four categories based on location 1. Periorbital 2. Nasal 3. Submental 4. Lower neck region.[1],[2]

The periorbital cyst, most common, occurs at the embryological maxillary and mandibular processes in the naso-optic groove. The nasal cyst develops at the bridge of the nose near the frontonasal plate. The submental cyst are found in the submental region where the first and the second branchial arches have fused in the midline. The lower neck cyst is the rarest, are seen at midventral or mid-dorsal embryological fusion site: thyroidal, suprasternal, or suboccipital.[1],[2]

Dermoid cysts are of three types - epidermoid cyst, true dermoid cyst and teratoid cyst. These are benign lesions described as cystic structures, if lined by simple squamous epithelium then called epidermoid cyst, and if it contains skin adnexa then true dermoid cyst, and if it contains tissue of all three germ layers then called teratoid cyst.

\section{PRESENTATION OF CASE}

Here we are presenting the case of a 34 years old male who came to our OPD in MMIMSR with chief complaints of midline swelling over lower neck since 4-5 years, which was insidious in onset and progressive in nature. Patient had gone to some local hospital. FNAC done at local hospital was suggestive of epidermal inclusion cyst after which swelling got burst and decreased in size, and discharge was mucoid and copious in amount, and started coming out of it. Excision was done under GA at our hospital.

\author{
Corresponding Author: \\ Soniya Arora, \\ Room No. 115, I-Block \\ MMIMSR Campus, \\ Mullana, Ambala-133207, \\ Haryana, India. \\ E-mail:drsoniya@hotmail.com \\ DOI: $10.14260 /$ jemds/2020/240 \\ Financial or Other Competing Interests: \\ None. \\ How to Cite This Article: \\ Datta G, Arora S, Chandra $S$, et al. A rare \\ case of epidermoid cyst at suprasternal \\ notch in an adult. J. Evolution Med. Dent. \\ Sci. 2020;9(13):1113-1115, DOI: \\ $10.14260 /$ jemds/2020/240
}

Submission 08-12-2019,

Peer Review 08-03-2020,

Acceptance 13-03-2020,

Published 30-03-2020.

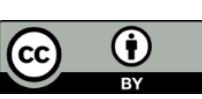




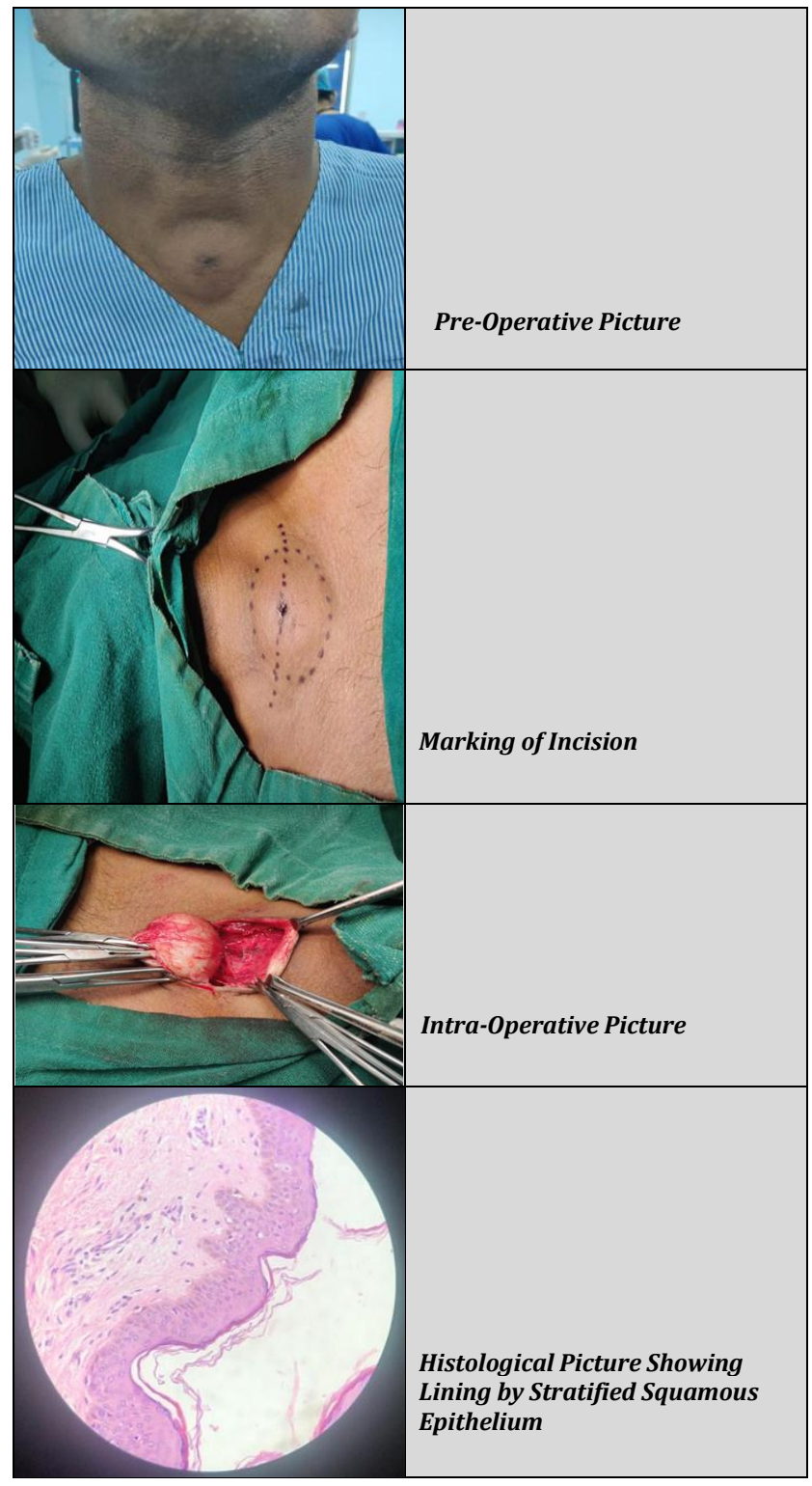

On inspection, the mass was the size of a lemon, round in shape, present at the suprasternal notch roughly measuring 4 $\mathrm{x} 3 \mathrm{cms}$, it had a smooth surface, fixed base with a punctum in the center. On palpation the mass was soft, smooth surface, margins well defined, not mobile during swallowing, mobile on vertical and horizontal movement and was non-tender, transillumination absent. Skin overlying the swelling was normal but adherent to anterior surface at some places and free from rest all the sides. No bruit present. FNAC has been repeated at our hospital suggestive of epidermal inclusion cyst. USG done which was also suggestive of epidermal inclusion cyst.

After doing all the routine investigations, excision was done under general anesthesia. Semilunar incision given in one of the skin lines along the neck crease. The intact mass was excised. Grossly, the external surface was smooth. The overlying skin on the anterior surface was fibrosed and tightly adherent to cyst because of the previous infection and free from rest of all sides. The mass contained serous fluid and the inner surface was smooth. Histopathological examination revealed - Grossly, cut section shows a unilocular cyst with drained out contents and smooth inner lining and thickened wall. Microscopically, sections show skin covered tissue with a cyst in the subcutis. The lining of the cyst was stratified squamous epithelium with intact granular layer and in situ keratin flakes in the luminal layer. The wall was composed of fibrocollagenous tissue. No dysplasia or malignancy noted. Impression suggestive of epidermal inclusion cyst.

\section{DIFFERENTIAL DIAGNOSIS}

Differential diagnosis includes true dermoid cyst, thyroglossal duct cyst, bronchogenic cyst, thymic cyst. [10]

\section{PATHOLOGICAL DISCUSSION}

Histopathological examination revealed - Grossly, cut section shows a unilocular cyst with drained out contents and smooth inner lining and thickened wall. Microscopically, sections shows skin covered tissue with a cyst in the subcutis. The lining of the cyst was stratified squamous epithelium with intact granular layer and in situ keratin flakes in the luminal layer. The wall was composed of fibrocollagenous tissue. No dysplasia or malignancy noted. Impression suggestive of epidermal inclusion cyst.

Grossly the epidermoid cyst contains whitish yellow material which has cheese like consistency and was covered by 2-6 $\mathrm{mm}$ thick fibrous capsule. The epidermoid cyst have shown least malignant potential. Other studies have shown proof of malignancy. But in our case histopathology showed no malignant potential.

Formation of dermoid cyst has been explained by many theories, they are developed in the fetal development period because of the trapping of ectodermal layer of first and second branchial arches. They may appear as a variant of thyroglossal cyst, previous surgeries and accidents could lead to trauma with implantation of epithelial cells into deeper tissues.[3],[4],[5],[6] The most important difference between a true dermoid cyst and an epidermoid cyst is the presence of skin appendages (e.g. sebaceous glands, hair follicles) within the wall of dermoid cyst and absence of these features is epidermoid. [7]

Most common region in the neck is the floor of the mouth. ${ }^{[8]}$ Approximately 7\% of dermoids are found in head and neck.[9] The most common clinical appearance of a dermoid cyst in the neck is a midline, suprahyoid slow growing mass.[10]

Imaging plays an important part in confirmation of diagnosis and it classifies the cyst according to its relation to the muscle. The initial investigation of choice is ultrasonography. In our case also USG was the investigation of choice in which epidermoid cysts were seen as circumscribed hypoechoic masses.

\section{DISCUSSION OF MANAGEMENT}

The mainstay treatment for such intraoral epidermoid cysts is usually total excision as needle aspiration could cause infection, pain, and complaints after procedure. Marsupialisation can also be considered as management of 
large cysts. In our case also we excised the cyst as a whole under general anesthesia.

Such cysts may alter in size, cause leakage and get inflamed, and so it is recommended to remove even the asymptomatic cysts.[11] The reason behind early excision is to prevent secondary infection. In our case also swelling got burst after FNAC which leads to secondary infection which was reason of excision.

\section{REFERENCES}

[1] McAvoy JM, Zuckerbraun L. Dermoid cysts of the head and neck in children. Arch Otolaryngol 1976;102 (9):529-31.

[2] New GB, Erich JB. Dermoid cysts of the head and neck. Surg Gynecol Obstet 1937;65:48-55.

[3] Jham BC, Duraes GV, Jham AC, et al. Epidermoid cyst of the floor of the mouth: a case report. J Can Dent Assoc 2007;73 (6):525-8.

[4] Pereira CM, Gasparetto PF, de Lucena Botelho T. Atypical appearance of epidermoid cyst in tongue's ventral surface. RSBO 2011;8 (2):240-2.
[5] Mirza S, Fadl S, Napaki S, et al. Case report of complicated epidermoid cyst of the floor of the mouth: radiologyhistopathology correlation. Qatar Med J 2014;2014 (1):12-6.

[6] Fuchshuber S, Grevers G, Issing WJ. Dermoid cyst of the floor of the mouth -- a case report. Eur Arch Otorhinolaryngol 2002;259 (2):60-2.

[7] Hunter TB, Paplanus SH, Chernin MM, et al. Dermoid cyst of the floor of the mouth: CT appearance. AJR Am J Roentgenol 1983;141 (6):1239-40.

[8] Koeller KK, Alamo L, Adair CF, et al. Congenital cystic masses of the neck: radiologic-pathological correlation. Radiographics 1999;19 (1):121-46.

[9] Holt GR, Holt JE, Weaver RG. Dermoids and teratomas of the head and neck. Ear Nose Throat J 1979;58 (12):52031.

[10] Som P. Cystic lesions of the neck. Postgrad Radiol 1987;7:211-36.

[11] Han HH, Ju RK, Seo BF, et al. Dermoid cyst excision under müller muscle in a patient with blepharoptosis. Arch Plast Surg 2014;41 (5):607-9. 